\title{
Chemoenzymatic Approaches to the Montanine Alkaloids: A Total Synthesis of $(+)$-Brunsvigine
}

2007

Vol. 9, No. 18

3503-3506

\author{
Martin G. Banwell, ${ }^{*}$ Okanya J. Kokas, and Anthony C. Willis
}

Research School of Chemistry, Institute of Advanced Studies, The Australian National University, Canberra, ACT 0200, Australia

mgb@rsc.anu.edu.au

Received June 7, 2007

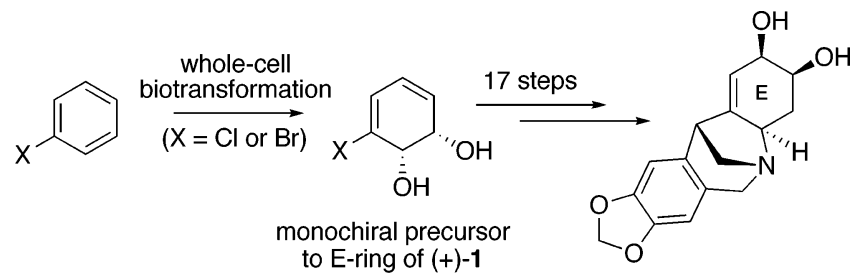

(+)-brunsvigine $[(+)-1]$

(non-natural enantiomer)

The readily available and enzymatically derived cis-1,2-dihydrocatechols $3 a$ and $3 b$ have been elaborated over 17 steps, including a novel radical addition/elimination sequence, into the enantiomer, $(+)-1$, of the montanine alkaloid brunsvigine [(-)-1].

(-)-Brunsvigine $[(-)-1]^{1-3}$ is a representative member of a relatively small group of natural products known as the montanine alkaloids which incorporate the 5,11-methanomorphanthridine framework and bear hydroxy or methoxy groups in varying configurations at C-2 and C-3. ${ }^{4}$ The isolation of (+)-montabuphine, ${ }^{5}$ assigned structure 2 , from the Amaryllidaceae species Boophane flava found in Southern Africa suggests that both enantiomeric forms of the framework can be encountered within this class of natural product. Little is known about the biological properties of such compounds, ${ }^{4,6}$ although their structural similarity to other pharmacologically active Amaryllidaceae alkaloids suggests they deserve attention in this regard.

(1) Dry, L. J.; Poynton, M.; Thompson, M. E.; Warren, F. L. J. Chem. Soc. 1958, 4701.

(2) Inubushi, Y.; Fales, H. M.; Warnhoff, E. W.; Wildman, W. C. J. Org. Chem. 1960, 25, 2153.

(3) Clark, R. C.; Warren, F. L.; Pachler, K. G. R. Tetrahedron 1975, 31, 1855.

(4) For reviews dealing with this class of alkaloid, see: (a) Martin, S. F. In The Alkaloids; Brossi, A., Ed.; Academic Press: San Diego, 1987; Vol. 30, p 251. (b) Hoshino, O. In The Alkaloids; Cordell, G. A., Ed.; Academic Press: San Diego, 1998; Vol. 51, p 323. (c) Lewis, J. R. Nat. Prod. Rep. 2000, 17, 57 and previous reviews in the series.

(5) Viladomat, F.; Bastida, J.; Codina, C.; Campbell, W. E.; Mathee, S. Phytochemistry 1995, 40, 307.
Two distinct end-games have been employed in the limited number of total syntheses of the montanine alkaloids reported

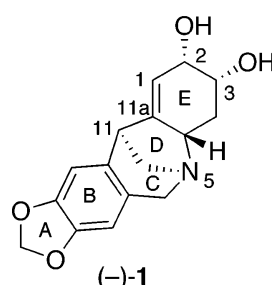

$(-)-1$

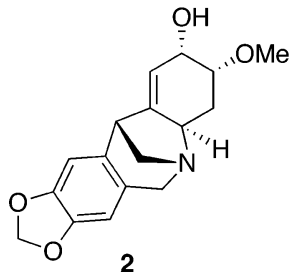<smiles></smiles>

$(+)-1$<smiles>[X]c1cccc(O)c1O</smiles>

$3 \mathbf{a} X=\mathrm{Cl}$
$\mathbf{3 b} \mathrm{X}=\mathrm{Br}$ thus far. The first of these, as highlighted in Overman's 1992 synthesis of ( \pm -pancracine, ${ }^{7}$ involves subjecting an appropriately configured 3-arylated perhydroindole to the Pictet-Spengler reaction. Pearson has exploited this same approach in the preparation of $(+)$-coccinine, ${ }^{8}$ as has Sha in a synthesis of $(-)$-brunsvigine. ${ }^{9}$ The second type of end- 
game relies on the assembly of the morphanthridine skeleton incorporating a hydroxymethyl group at C-11 and installation of the 5,11-methano bridge by activation of the hydroxyl moiety, then displacement of the activated unit by N-5. Hoshino first deployed this approach in syntheses of $( \pm)$ montanine, $( \pm)$-coccinine, $( \pm)$ - $O$-acetylmontanine, $( \pm)$-pancracine, and $( \pm)$-brunsvigine. ${ }^{10}$ Subsequently, Weinreb applied this strategy in enantioselective total syntheses of $(-)$ montanine, (-)-coccinine, and (-)-pancracine. ${ }^{11}$ Several formal total syntheses of various members of the montanine alkaloid class have also been described, ${ }^{12}$ and all but two ${ }^{12 a, d}$ rely on one or other of the two end-games just described. Herein we outline a chemoenzymatic synthesis of the enantiomer, $(+)-\mathbf{1}$, of $(-)$-brunsvigine $[(-)-\mathbf{1}]$ that starts from the monochiral 3-halo-cis-1,2-dihydrocatechols $\mathbf{3 a}$ and $\mathbf{3 b}$, each of which can be obtained in multigram quantities through the whole-cell biotransformation of the corresponding halobenzene..$^{13}$ The strategy used involves the late-stage application of the Pictet-Spengler reaction and a novel radical addition/elimination process ${ }^{14}$ that permits the ready and completely regiocontrolled introduction of the $\Delta^{1,11 a_{-}}$ alkene associated with all of the title alkaloids.

The early stages (Scheme 1) of the total synthesis of (+)brunsvigine involved assembly of the precursor to the E-ring and began with the $p$-methoxyphenyl or PMP-based acetal derivatives $4,{ }^{15}$ of compounds $\mathbf{3 a}$ and $\mathbf{3 b}$. These acetals were subjected to a regio- and diastereo-selective cis-dihydroxylation under the UpJohn conditions, ${ }^{16}$ and the resulting diols $\mathbf{5 a}(65 \%$ from 3a) and $\mathbf{5 b}(66 \%)$ converted, under standard conditions involving $\mathrm{MOM}-\mathrm{Cl}$ and sodium hydride, into the corresponding bis-MOM ethers $\mathbf{6 a}(91 \%)$ and $\mathbf{6 b}(88 \%)$, respectively. Reductive cleavage of the acetal moiety within these last compounds was effected regioselectively using DIBAL-H ${ }^{15}$ affording the $p$-methoxylbenzyl or PMB-ethers 7a $(64 \%)$ and $\mathbf{7 b}(60 \%)$, respectively. Conversion of these alcohols into the corresponding iodides, $\mathbf{8 a}(81 \%)$ and $\mathbf{8 b}$ $(66 \%)$, could be achieved using triiodoimidazole in the

(6) Very recently (-)-montanine has been shown to display anxiolytic, antidepressant and anticonvulsant-type effects in mice: Schürmann da Silav, A. F.; de Andrade, J. P.; Bevilaqua, L. R. M.; da Souza, M. M.; Izquierdo, I.; Henriques, A. T.; Zuanazzi, J. A. S. Pharmacol., Biochem. Behav. 2006, 85,148 .

(7) Overman, L. E.; Shim, J. J. Org. Chem. 1991, 56, 5005.

(8) Pearson, W. H.; Lian, B. W. Angew. Chem., Int. Ed. 1998, 37, 1724.

(9) Sha, C.-K.; Hong, A.-W.; Huang, C.-M. Org. Lett. 2001, 3, 2177.

(10) Ishizaki, M.; Hoshino, O.; Iitaka, Y. J. Org. Chem. 1992, 57, 7285.

(11) Jin, J.; Weinreb, S. M. J. Am. Chem. Soc. 1997, 119, 5773.

(12) (a) Ishizaki, M.; Kurihara, K.-I.; Tanazawa, E.; Hoshino, O. J. Chem. Soc., Perkin Trans. 1 1993, 101. (b) Ikeda, M.; Hamada, M.; Yamashita, T.; Matsui, K.; Sato, T.; Ishibashi, H. J. Chem. Soc., Perkin Trans. 11999 , 1949. (c) Banwell, M. G.; Edwards, A. J.; Jolliffe, K. A.; Kemmler, M. J. Chem. Soc., Perkin Trans. 1 2001, 1345. (d) Pandey, G.; Banerjee, P.; Kumar, R.; Puranik, V. G. Org. Lett. 2005, 7, 3713.

(13) For reviews on methods for generating cis-1,2-dihydrocatechols by microbial dihydroxylation of the corresponding aromatics, as well as the synthetic applications of these metabolites, see: (a) Hudlicky, T.; Gonzalez, D.; Gibson, D. T. Aldrichimica Acta 1999, 32, 35. (b) Banwell, M. G.; Edwards, A. J.; Harfoot, G. J.; Jolliffe, K. A.; McLeod, M. D.; McRae, K. J.; Stewart, S. G.; Vögtle, M. Pure Appl. Chem. 2003, 75, 223. (c) Johnson, R. A. Org. React. 2004, 63, 117.

(14) Stanislawski, P. C.; Willis, A. C.; Banwell, M. G. Org. Lett. 2006, $8,2143$.

(15) Compound 4b has been described previously: Banwell, M. G.; McRae, K. J.; Willis, A. C. J. Chem. Soc., Perkin Trans. 1 2001, 2194. 1973.

(16) VanRheenen, V.; Kelly, R. C.; Cha, D. Y. Tetrahedron Lett. 1976

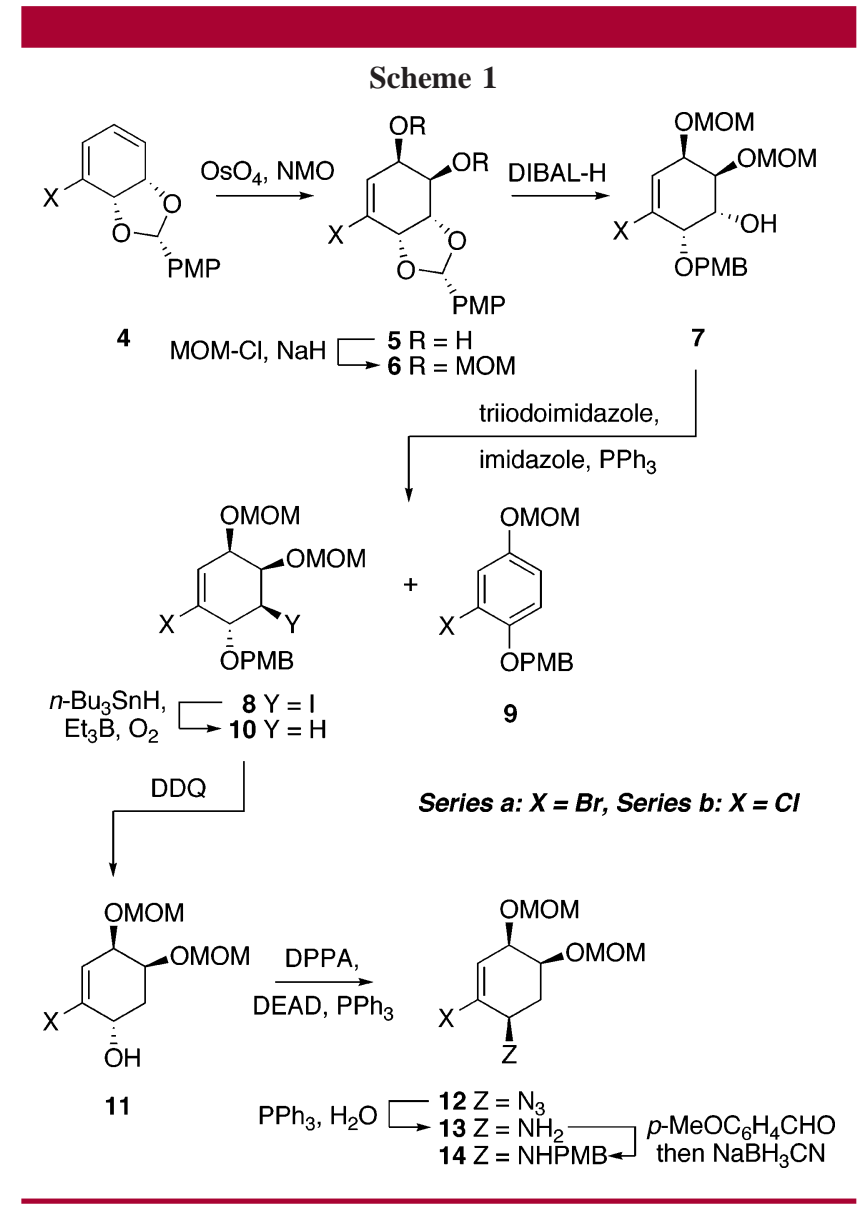

presence of imidazole and triphenylphosphine, ${ }^{17}$ although in each of these reactions leading to such products they were accompanied by the hydroquinone derivative $9(2.5-6 \%)$. The structures of compounds $8 \mathbf{a}$ and $\mathbf{9 b}$ follow from singlecrystal X-ray analyses. ${ }^{18}$ Reductive deiodination of dihalides $\mathbf{8 a}$ and $\mathbf{8 b}$ was achieved using tri- $n$-butyltin hydride and without any complications arising from competitive removal of the halogens attached to the associated alkene. The ensuing PMB-ethers 10a (85\%) and 10b $(84 \%)$ were each subjected to cleavage with DDQ, and the alcohols 11a (96\%) and 11b (98\%) so formed engaged in Mitsunobu reactions using diphenylphosphoryl azide (DPPA) $)^{19}$ as the nucleophile. The ensuing azides 12a (93\%) and 12b (75\%) thus formed were then each subjected to a Staudinger reaction using triphenylphosphine in aqueous THF, and the resulting primary amines 13a (87\%) and 13b (98\%) engaged in reductive amination reactions using $p$-methoxybenzaldehyde then sodium cyanoborohydride to give the corresponding secondary amines $\mathbf{1 4 a}(90 \%)$ and $\mathbf{1 4 b}(56 \%)$.

The assembly of the precursor to the AB-ring substructure of (+)-brunsvigine is shown in the early parts of Scheme 2 and used protocols defined by Ikeda et al. ${ }^{12 b}$ Thus, 1,2methylenedioxybenzene was treated with ethyl $\alpha$-chloro- $\alpha$ -

(17) Garegg, P. J.; Samuelsson, B. J. Chem. Soc., Perkin Trans. 1 1980, 2866.

(18) Details of X-ray analyses carried out as part of this study are provided in the Supporting Information.

(19) Lal, B.; Pramanik, B. N.; Manhas, M. S.; Bose, A. K. Tetrahedron Lett. 1977, 1977. 


\section{Scheme 2}

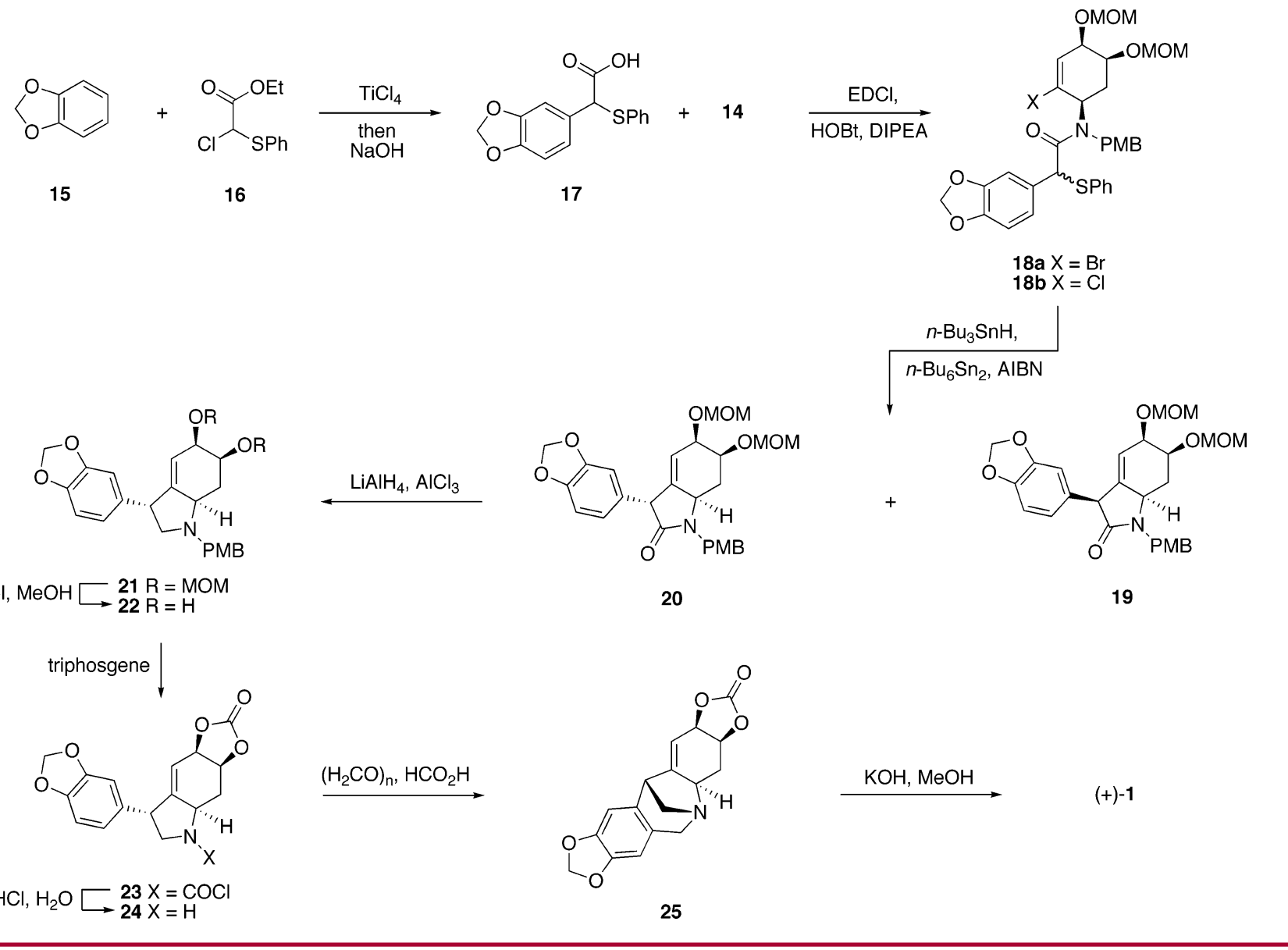

thiophenylacetate in the presence of $\mathrm{TiCl}_{4}$ to give, after saponification of the product ester with $\mathrm{NaOH}$, the $\alpha$-arylated acetic acid 17 (99\%). EDCI-promoted coupling of this compound with either amine $\mathbf{1 4 a}$ or $\mathbf{1 4 b}$ gave the corresponding amides $\mathbf{1 8 a}(86 \%)$ and $\mathbf{1 8 b}(74 \%)$, each of which was obtained as a ca. 1:1 mixture of diastereoisomers. In a pivotal step of the synthesis, compounds $\mathbf{1 8 a}$ and $\mathbf{1 8 b}$ were each subjected to reaction with mixtures of hexa- $n$-butylditin, tri- $n$-butyltin hydride, and AIBN so as to generate, via homolytic cleavage of the thiophenyl unit, a benzylic radical that engages in a 5-exo-trig cyclization/halide radical elimination reaction sequence, ${ }^{14}$ thus forming the D-ring of target (+)-1. This sequence led to a mixture of the 3-arylhexahydrooxindole $19(0 \%$ from $\mathbf{1 8 a}$ and $7 \%$ from $\mathbf{1 8 b})$ and the required epimer 20 (29\% from 18a and 60\% from 18b) together with varying quantities of those compounds arising from reductive cleavage of the thiophenyl and/or halogen residue within the starting materials. The lactam carbonyl within product 20 was removed using in situ generated $\mathrm{AlH}_{3}$ and the hexahydroindole 21 thus obtained in 94\% yield. Because the looming Pictet-Spengler reaction requires the presence of acid-stable hydroxyl protecting groups, the MOM-ether residues within compound 21 were removed using aqueous $\mathrm{HCl}$ in methanol and the ensuing diol 22 $(73 \%)$ subjected to reaction with triphosgene. ${ }^{20}$ Use of this reagent not only resulted in the conversion of the cis-diol residue within substrate $\mathbf{2 2}$ into the acid-stable cyclic carbonate but also effected cleavage of the PMB-protected amine to form the corresponding carbamoyl chloride $\mathbf{2 3}$ which was immediately treated with aqueous dioxane in the presence of traces of $\mathrm{HCl}$ to give the cyclic secondary amine 24 (42\% from 22). Treatment of the last compound with paraformaldehyde in aqueous formic acid at $80^{\circ} \mathrm{C}$ effected the pivotal Pictet-Spengler reaction to generate compound $25(65 \%)$ embodying the full pentacyclic framework of target (+)-brunsvigine. Finally, subjection of carbonate $\mathbf{2 5}$ to reaction with $\mathrm{KOH}$ in methanol at $18{ }^{\circ} \mathrm{C}$ afforded compound (+)-1 [mp $130-140{ }^{\circ} \mathrm{C}$ (sesquihydrate-recrystallized from wet acetone); lit. ${ }^{1} \mathrm{mp} 140-150{ }^{\circ} \mathrm{C}$ (for sesquihydrate of the enantiomer)] in $87 \%$ yield. The spectral data derived from this material were in full accord with the assigned structure, but final confirmation of this followed from a single-crystal X-ray analysis. ${ }^{18}$ The specific rotation of $(+)$-brunsvigine $\left\{[\alpha]_{\mathrm{D}}+75.9\right.$ ( $c 0.1$, ethanol) $\}$ was of similar magnitude but opposite sign to that reported ${ }^{21}$ for its enantiomer $\left\{[\alpha]_{D}\right.$ -76.3 (c 1, ethanol)\}.

Given the availability of the enantiomeric forms of starting materials $\mathbf{3 a}$ and $\mathbf{3 b},{ }^{13}$ the work detailed above will also

(20) Banwell, M. G.; Coster, M. J.; Harvey, M. J.; Moraes, J. J. Org. Chem. 2003, 68, 613.

(21) Pancricine. Dictionary of Natural Products; Buckingham, J., Ed.; Chapman \& Hall: London, U.K., 1994; Vol. 4, p 4432, entry P-00106. 
provide access to (-)-brunsvigine. Moreover, it seems reasonable to suggest that rather straightforward modifications to the reaction sequences defined above should permit the efficient preparation of many other members of the montanine alkaloid class. Work directed to such ends is now underway in these laboratories, and results will be reported in due course.

Acknowledgment. We thank the Institute of Advanced Studies and the Australian Research Council for generous financial support.
Supporting Information Available: Preparation and characterization of selected compounds; atomic displacement ellipsoid plots together with certain other materials derived from the single-crystal X-ray analyses of compounds $8 \mathbf{a}, \mathbf{9 b}$, and (+)-1 (CCDC numbers 632321, 632322, and 641134, respectively); and ${ }^{1} \mathrm{H}$ or ${ }^{13} \mathrm{C}$ NMR spectra of compounds $11 a$, 11b, 14a, 14b, 20, 25, and (+)-1. This material is available free of charge via the Internet at http://pubs.acs.org.

OL071344Y 